\title{
Glutathione S-transferase Isoenzymes in Lung Carcinoma Patients receiving Platinum-based Chemotherapy and Effects of Ethyl Alcohol and Smoking on Treatment Response
}

\author{
Celalettin Semih Kunak* \\ Ordu University, Faculty of Medicine, Department of Medical Pharmacology, Ordu,Turkey
}

Submission: January 24, 2020; Published: February 18, 2020

"Correspondence Author: Celalettin Semih Kunak, Ordu University, Faculty of Medicine, Department of Medical Pharmacology, Ordu, Turkey

\begin{abstract}
Mostly observed in men, lung carcinoma ${ }_{\llcorner}$mostly observed in men $_{\perp}$ is one of the most frequent cancer types in Turkey and in the world. About two thirds of the lung carcinoma patients have inoperable lesions. 113 primary lung cancer patients who were receiving platinum based treatment at Chest Diseases and Chest Surgery Center of Ankara Atatürk Hospital were enrolled for the study. It was identified that 49 (43\%) patients had GSTM1 gene deletion out of a group of 113. It was identified that 42 (\%), 34 (39\%) and 10 (12\%) patients had GSTP1 İle $_{105} /$ lle $_{105}$ (wild type) genotype, $\dot{l} \mathrm{e}_{105} / \mathrm{Val}_{105}$ (heterozygote) genotype and $\mathrm{Val}_{105} / \mathrm{Val}_{105}$ (homozygote mutant) genotype, respectively out of a group of 113 . GSTP1 is the most strongly expressed isoenzyme in the human lung. In this study, the responses to cisplatine based chemotherapy of homozygous and heterozygous patients with GSTP1 exon5 variant allele were observed to be similar to the responses of the patients carrying wild type genotype. it is displayed that wild type genes have positive effect on the response to treatment. This result yields that it is important to evaluate the effect of combination of GST genotype, alcohol ingestion amount, smoking frequency on the response to treatment
\end{abstract}

Keywords: Glutathione S-transferase; Lung Carcinoma; Platinum-based Chemotherapy

\section{Introduction}

\begin{tabular}{|l}
\hline Trachea, Broncihial, Lung \\
Prostate \\
Bladder \\
Colorectal \\
Stomach \\
Larynx \\
Non-Hodgkin Lenfoma \\
Kidney \\
Pancreatic \\
Brain, nervous system
\end{tabular}

Distribution of age-standardised incidence for the first frequently observed 10 cancers among men (United Data Base, 2009)(World's Standard population, among 100.000 persons)

Figure 1: 2009 Data from MoH Cancer Department.

Mostly observed in men, lung carcinoma, mostly observed in men $_{\mathbf{L}}$ is one of the most frequent cancer types in Turkey and in the world, and it ranks the first in Turkey in terms of mortality from cancer (Figures $1 \& 2$ ). About two thirds of the lung carcinoma patients have inoperable lesions. Even if these patients receive the most effective chemotherapy regimen, a significant part of 


\section{Cancer Therapy \& Oncology International Journal}

them dies within a year. "Non-small cell lung carcinoma" patients which constitute $80-85 \%$ of the carcinoma cases, respond to chemotherapy is $30-50 \%$ [1-3]. For this reason, it is very important to conduct a search for the failure of chemotherapy in treatment of these patients.

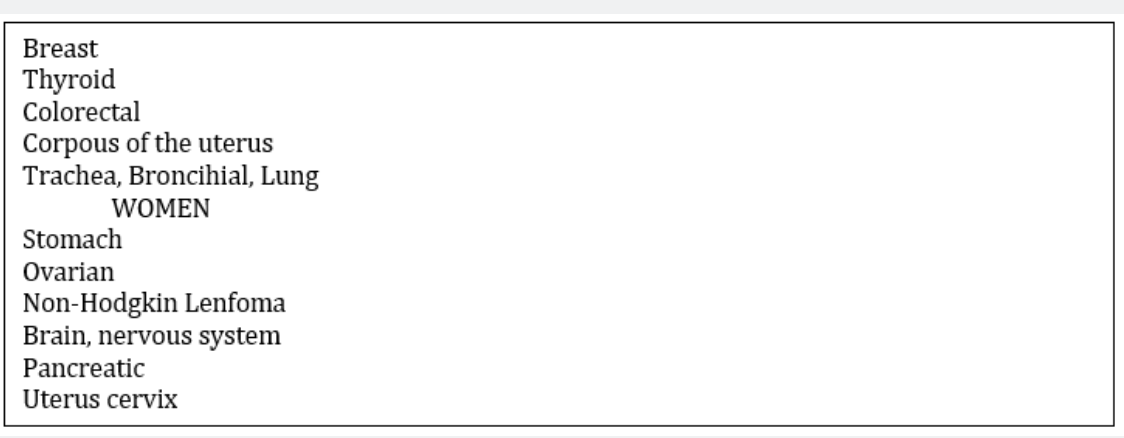

Distribution of age-standardised incidence for the first frequently observed 10 cancers among women (United Data Base, 2009)(World's Standard population, among 100.000 persons)

Figure 2: 2009 Data from MoH Cancer Department.

Within this respect, the studies on mechanisms of drug resistance have been intensified recently and it is found that certain factors play roles in chemoresistance of cancer cells. It is thought that the gluthione s-transferases (GST) may be one of these factors. Catalyzing phase II reactions, GSTs are a superfamily of a dimeric nature and have a significant role in cellular defense system. GSTs protect cellular macromolecules from damages by catalyzing the conjugation of toxic and carcinogenic electrophilic molecules with glutathione [4] Certain data indicate that GSTs determine the cytotoxic effect of various chemotherapy drugs. GSTs consist of 8 subfamilies namely as (alpha, $[\alpha]$; kappa, $[\kappa]$; $\mathrm{mu},[\mu]$; pi, $[\pi]$; sigma, $[\sigma]$; theta, $[\theta]$; zeta, $[\zeta]$; and omega, $[\omega])$ and each class may have different variant isoforms. GSTP1 is the most strongly expressed isoenzyme in the human lung [5]. GSTM1 and GSTT1 isoenzymes are expressed in the lung, though lesser. GSTP1 is known as to be the most expressed GST in nonsmall cell lung tumors [6]. It is determined that GSTP1 levels of drug resistant tumors are high. Among these, non-small cell lung tumors are remarkable. It is argued that GSTP1 directly participates in the detoxification of platinum components and that it plays a significant role in both intrinsic and acquired resistance to platinum components [7]. However, there are studies demonstrating that platinum resistance is not associated with GSTP1. Similar contradictory results were presented for ovarian carcinoma.

One of the important reasons for not being able to demonstrate the correlation between GSTP1 expression and platinum components at any time, may be the polymorphism of GSTP1 gene. It is well-known that GSTP1 gene is polymorphic. Three different alleles were described; GSTP1*A (wild type), GSTP1* $B$ and $G S T P 1^{*} C$. The $G S T P 1^{*} B$ variant shows an $A \rightarrow G$ transition at position +313 , codon 105 , exon 5 , changing the amino acid Ile to Val [8]. The $G S T P{ }^{*} C$ allele has 2 transitions, the same as those observed in the GSTP1*B allele and a second one, located at position +314 , codon 106 , exon 6 , changing the amino acid Ala to Val. The $\mathrm{Ile}_{105}{ }^{\circledR V} \mathrm{Val}_{105}$ substitution in the ${ }^{*} B$ and ${ }^{*} C$ variants reduces the catalytic activity of the enzyme (5) [9]. Thus, the carriers of mutant alleles can not metabolize carcinogens sufficiently, which could be responsible for a higher susceptibility to cancer.

Moreover, it is reported that GSTM1 and GSTT1 may be effective in the formation of several carcinomas, including lung carcinoma, and in treatment responses [10]. Since GSTM1 and GSTT1 genes are also polymorphic, lack of these genes results in loss of enzyme activities. Reduction in and loss of the activities of these polymorphic GSTs may decrease the detoxification of platinum components. This situation, by strengthening the cytotoxic effects of components and thus improving the treatment activities, increases the ratio of patient's response to the drugs.

Chronic alcohol ingestion disrupts mitochondiral structure and function, results in suppression of respiration, increasing of mitochondrial reactive oxygen species, decreasing of ATP and interruption of fatty acid metabolism. During alcohol metabolism, ethanol is converted into acetaldehyde by alcohol dehydrogenase $(\mathrm{ADH})$, and acetaldehyde is changed into acetate in mitochondria by mitochondrial aldehyde dehydrogenase (ALDH). Both reactions use $\mathrm{NAD}^{+}$as a co-factor. Later on, this is also converted into $\mathrm{NADH}$. Alterations in cellular $\mathrm{NAD}^{+} / \mathrm{NADH}$ ratio caused by alcohol lead to decrease in ATP synthesis. As a result, disruptions in electron transport chain will lead to elevation of mitochondrial superoxide anions, $\mathrm{H} 2 \mathrm{O} 2$ and hydroxyl radicals. Alcohol also has effects on cellular antioxidant defence mechanisms as well as on the formation of reactive oxygen species. It is demonstrated during the studies with rat model that chronic alcohol ingestion decreased the cellular GSH pool of alveolar Type 2 (ATII) cells and this resulted in the decrease in surfactant sythesis and 
secretion which is vital [11]. The balance of intracellular oxidants and antioxidant systems is critical in the regulation of receptors and cytokines in the immune response. Decreased surfactant processing will lead to decreased barrier integrity and increased apoptosis. Alcohol induced reactive oxygen species generation and GSH oxidation may alter the response of other immune cells. Decrease in phagocytic capacity may be demonstrated as an example of this [12].

Effect of alcohol ingestion on systemic immune response was searched by using obese diabetic mice model and it was demonstrated that adaptive immune response was specifically suppressed in case of inflammation. It was demonstrated that low-dose alcohol ingestion disrupted immune response while it decreased the inflammatory response [13]. In another study carried out by using mice model demonstrated that short-term administration of alcohol negatively affected antigen presentation activity towards B cells [14].

Many studies were carried out concerning the role of smoking on the etiology of lung carcinoma. Various studies were conducted in order to search whether smoking or quitting smoking interferes with the response to treatment following the start of lung cancer treatment. It was observed that stopping smoking had very small positive effect on treatment while continuing to smoke decreased the effect of treatment and increased the recurrence frequency [15]. It is observed in mice model that nicotine decreased the chemotherapeutic effect of gemcitabine, resulted in tumor progression and elevated metastasis frequency although nicotine, itself, is not a carcinogen substance [16]. Human lung epithelium was used experimentally during the in vitro study and it was indicated that long term smoking elevated the resistance to chemotherapy in lung cancer. This study showed that decrease in Smad3 expression elevated carboplatine resistance in non-small cell lung cancer [17]. It is demonstrated through these studies that stopping smoking is mandatory for the success of lung cancer treatment. It was demonstrated that other factors also had role in prognosis of treatment during cisplatin based treatments. Polymorphisms in DNA repair genes and methylation of checkpoint genes in circulating serum DNA could have important predictive roles in survival in cisplatin-based treatment [3].

Platinum-based drugs such as cisplatin, carboplatin and oxaliplatin are frequently used in the treatment of cancer. Cisplatin is an organic, platinum derived drug which is different from other antineoplastics in terms of its structure. During the experiments conducted in order to examine the effect of electrical field which is formed in a liquid environment through platinum electrodes, on the growth of $e$. coli, it is incidentally noticed that platinum derivatives which were transferred into liquid from the electrodes had antibacterial and antineoplastic effects and thus cisplatin was discovered. Only its gis isomer is cytotoxic. It is not a period specific drug. It functions as an alkylating agent. It binds to DNA with covalent bonds via N-7 of guanine and adenine. Cisplatin affects DNA in two ways as it binds with DNA to form intrastrand (90\%) and interstrand (10\%) crosslinks. This results in DNA adduct formation or DNA synthesis and transcription. Binding to nucleoproteins and cytoplasmic proteins, it may result in cytotoxic effects [18].

Carboplatin is a cisplatin analogue with an antineoplastic activity like cisplatin, but having less emetic effect and decreased renal toxicity, ototoxicity and neurotoxicity. Carboplatin shows effect as it is transformed into cisplatin after it is injected to the organism. Carboplatin binds with DNA to form intrastrand (more than 90\%) and interstrand (less than 5\%) crosslinks. It inhibits DNA synthesis and function through forming DNA adduct. Furthermore, it prevents the transcription. Binding to nuclear and cytoplasmic proteins, it results in cytotoxic effects. Glutathione and glutathione-related enzymes increase its inactivation.

Establishing whether these polymorphic genes affect the responses to platinum-based chemotherapy in lung carcinoma is important in terms of being able to plan the treatment forms that are effective on personal basis, as a result. Thus, the aim of this study is to conduct a research on the effects on response of GSTM1, GSTP1 and GSTT1 gene polymorphisms of both small cell and non-small cell lung carcinoma patients receiving platinum based treatment when these gene polymorphisms are associated with alcohol ingestion and smoking.

\section{Materials and Methods}

113 primary lung cancer patients who were receiving platinum based treatment at Chest Diseases and Chest Surgery Center of Ankara Atatürk Hospital were enrolled for the study. Certain diagnostic methods were used for staging small cell lung cancer (SCLC) and non-small cell lung cancer (NSCLC): direct chest graphy, lung, surrenal and brain computed tomography, bone scintigraphy were used as imaging methods and fine-needle aspiration biopsy, bronchoscopic biopsy and biopsy methods applied through surgical operation were used for pathological diagnosis. Whether the patients responded to chemotherapy was evaluated radiologically in accordance with the criteria of World Health Organisation (WHO). During the evaluation of the replies, patients who replied the questions fully and partly were accepted as the patients who replied the questions. Stabile patients and patients with progression were included in the group of patients who did not reply.

The followings are the chemotherapy protocols used in lung cancer: 1) Gemcitabine+ Cisplatin 2) Docetaxel+ Cisplatin 3) Vinorelbine+ Cisplatin 4) Paclitaxel+ Carboplatin 5) Etoposide+ Cisplatin. During our study, the patients received treatment of at least two cures or more with 21 day-intervals. The radiological evaluations in accordance with WHO criteria were started to be conducted following the second cure. 


\section{Cancer Therapy \& Oncology International Journal}

\section{WHO tumor response criteria:}

Complete response: Disappearance of all symptoms radiologically.

Partial response: Tumor burden is decreased by $\geq 50 \%$.

Stable disease: Present tumor burden increased $<25 \%$ and decreased $<50$.

Progressive disease: Development of new lesions or growth of lesions $\geq 25 \%$.

Ethyl alcohol ingestion amounts were defined according to the CDC criteria. Accordingly, accepting that one standard unit has $14 \mathrm{gr}$ pure alcohol by volume, if the daily ingestion of alcohol is 2 units the male patient is considered as a medium drinker; the same applies for women whose daily ingestion of alcohol is 1 unit. Those whose daily ingestion is less than these amounts are accepted as light drinkers, and more than these amount, as heavy drinkers. Genomic DNA was isolated by (Promega) kit which is prepared according to the method of [19]. GSTM1 and GSTT1 genotypes were identified by multiplex PCR method as defined by [20]. Ile105Val and Ala114Val mutations in GSTP1 gene were made through PCR and RFLP methods [21].

\section{Statistical Analysis}

Chi-square analysis was used in order to demonstrate whether the response to treatment was associated with smoking habit and alcohol ingestion of the person, with GSTP1exon5 and GSTP1 exon6, GSTT1 and GSTM1. Logistic regression analysis was used for determining the possible factors having effect on nonresponse. SPSS Statistics 20.0 was used during analysis.

\section{Results}

\section{GSTM1 Genotype findings}

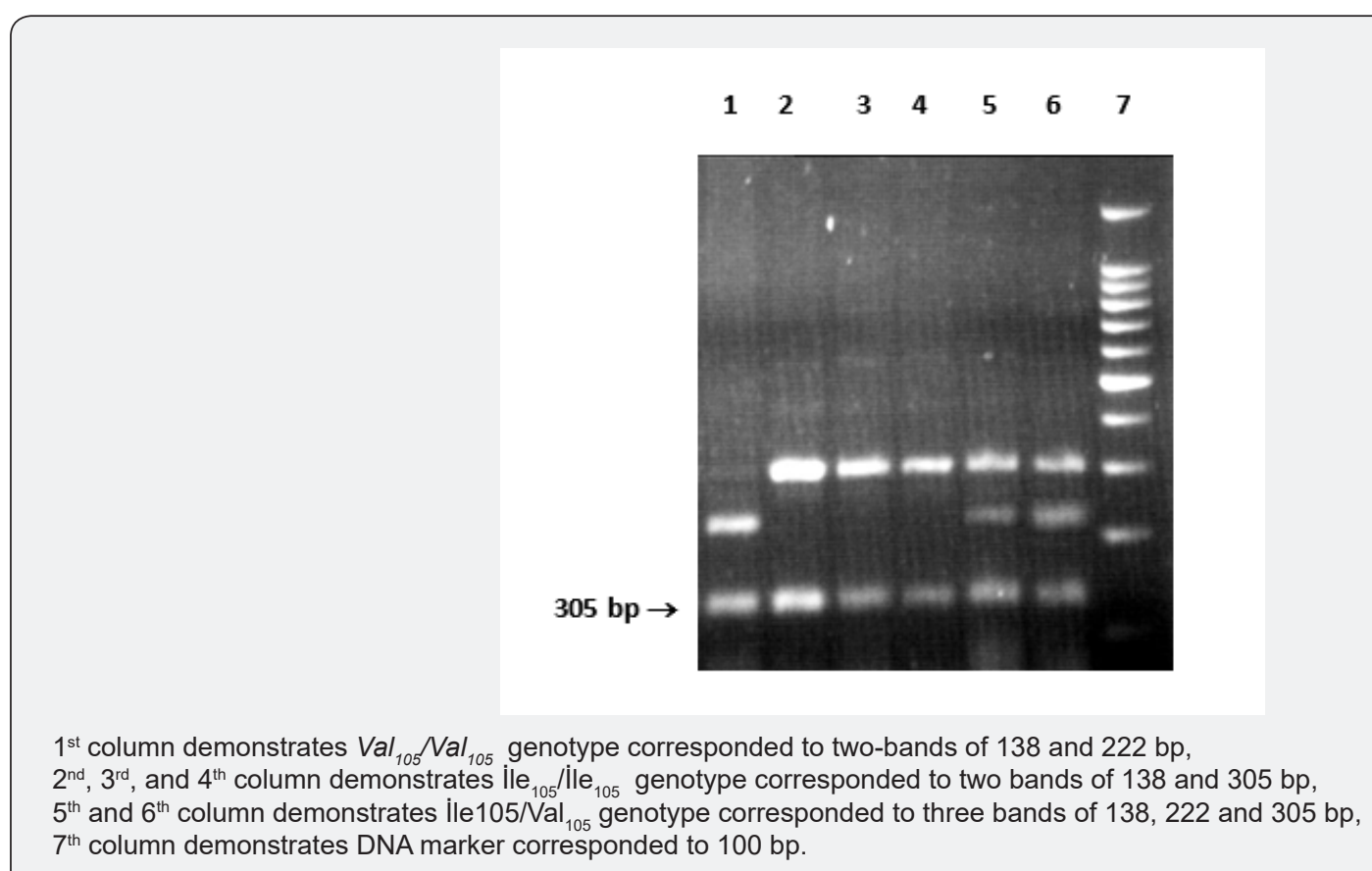

Figure 3: The result of electrophoresis which was used to determine the GSTP1 Ile105Val genotype.

It was identified that $49(43 \%)$ patients had GSTM1 gene deletion out of a group of 113 . The result of electrophoresis which was used to determine the GSTM1 genotype is displayed in Figure 3.

\section{GSTP1 Ile105Val genotype findings:}

It was identified that $42(\%), 34(39 \%)$ and $10(12 \%)$ patients had GSTP1 İle ${ }_{105} /$ Ille $_{105}$ (wild type) genotype, İle ${ }_{105} /$ $\mathrm{Val}_{105}$ (heterozygote) genotype and $\mathrm{Val}_{105} / \mathrm{Val}_{105}$ (homozygote mutant) genotype, respectively out of a group of 113 . The result of electrophoresis which was used to determine the GSTP1 Ille105Val genotype is displayed in Figure 3.

\section{GSTP1 Ala114Val genotype findings:}

It was identified that $64(74 \%)$ and $11(13 \%)$ patients had GSTP1 Ala ${ }_{114} / \mathrm{Ala}_{114}$ (wild type) genotype and $\mathrm{Ala}_{114} /$ $\mathrm{Val}_{114}$ (heterozygote) genotype, respectively out of a group of 113. $11(13 \%)$ patients were identified to have $\mathrm{Val}_{114} / \mathrm{Val}_{114}$ (homozygote mutant) genotype (Figure 4). 


\section{Cancer Therapy \& Oncology International Journal}

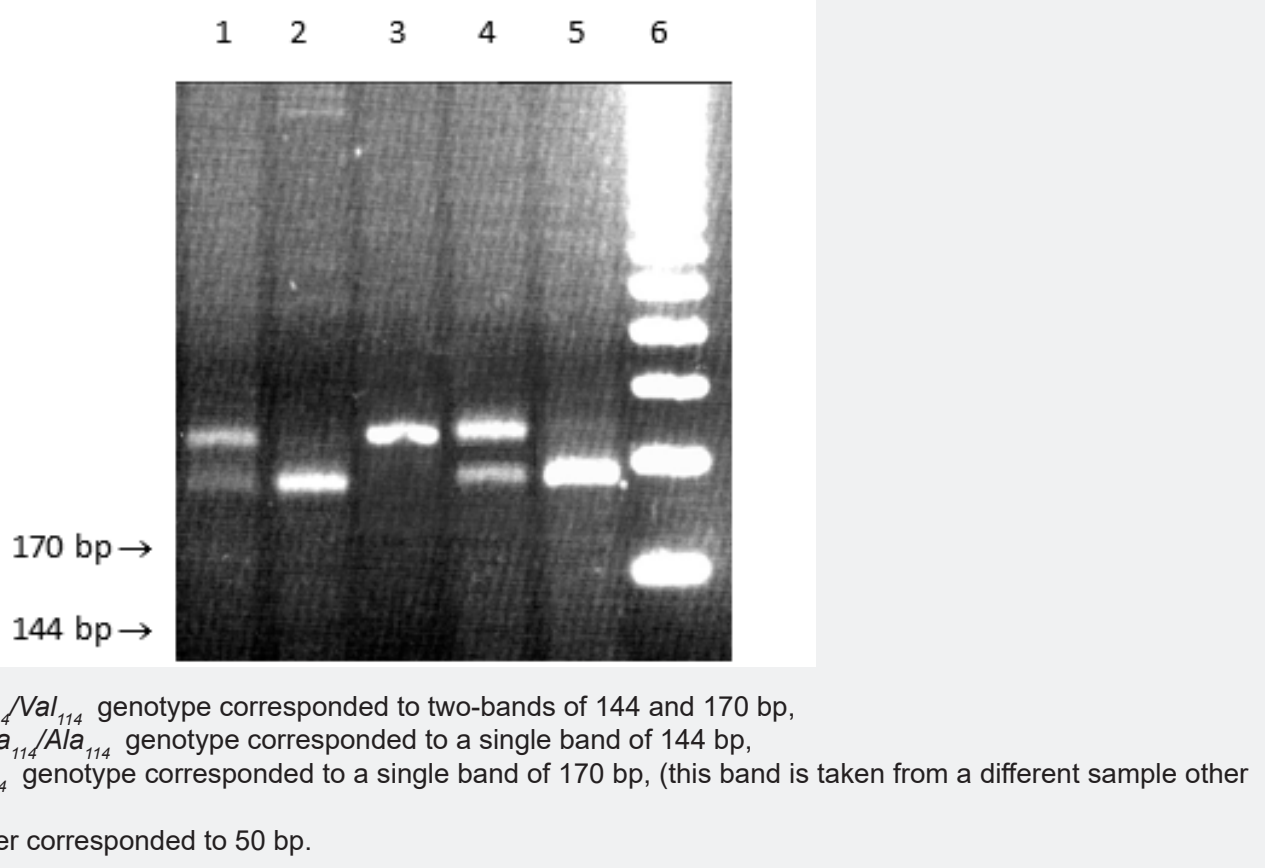

Figure 4: The result of electrophoresis which was used to determine the GSTP1 Ala114Val genotype.

\section{GSTT1 genotype findings}

It was identified that $85(75 \%)$ patients had GSTT1 gene deletion out of a group of 113 . The result of electrophoresis which was used to determine the GSTT1 genotype is displayed in Figure 5. GST isoenzymes of the patients enrolled for the study and their non-response to treatment were evaluated at Tables 1-4. Accordingly, distribution of isoenzymes and the rate of non- response among 113 patients were identified as follows: 84 wild type (69\%), 15 heterozygote (87\%), 14 mutant(93\%) for GST exon 6; and 59 wild type (73\%), 44 heterozygote (75\%), 10 mutant (\%80) for GST exon 5. It was observed that there were 49 patients (76\%) with GSTM1 and 64 patients (73\%) without GSTM1. Also 85 patients (74\%) had GSTT1 positive and 28 patients (75\%) had GSTT1 null genotype.

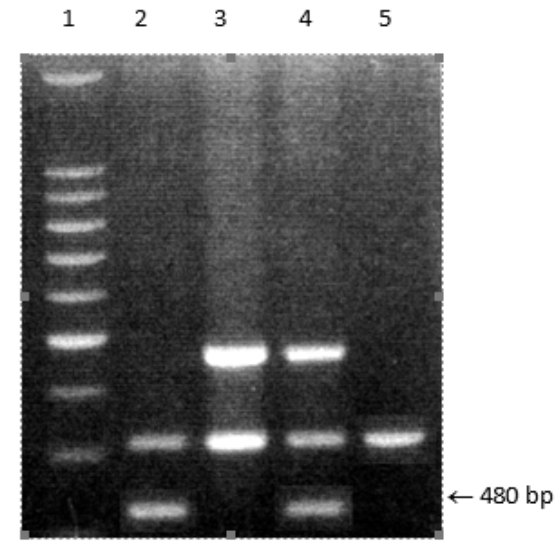

$1^{\text {st }}$ DNA marker corresponded to $100 \mathrm{bp}$,

$2^{\text {nd }}$ GSTM1 genotype corresponded to 215 bp band; and CYP1A1 corresponded to 312 bp band for the internal control, $3^{\text {rd }}$ GSTT1 genotype corresponded to 480 bp band; and CYP1A1 corresponded to 312 bp band for the internal control $4^{\text {th }}$ GSTM1 genotype corresponded to $215 \mathrm{bp}$ band; and CYP1A1 corresponded to $312 \mathrm{bp}$ band for the internal control, $5^{\text {th }}$ GSTM1 and GSTT1 deletion; and CYP1A1 corresponded to 312 bp band for the internal control.

Figure 5: The result of gel electrophoresis which was used to determine the GSTM1 and GSTT1 genotypes. 


\section{Cancer Therapy \& Oncology International Journal}

Table 1: Possible risk factors in "non-response" to treatment.

\begin{tabular}{|c|c|c|c|c|c|}
\hline GSTP1 Exon6 & Non-responder & Total number of patients & Prevalance (\%) & OR & 95 \% CI \\
\hline Wild type & 58 & 84 & 69,0 & - & - \\
\hline Heterozygote & 13 & 15 & 86,7 & 2,844 & $0,547-14,791$ \\
\hline Mutant & 13 & 14 & 92,9 & 9,757 & $1,002-95,024$ \\
\hline
\end{tabular}

Table 2: Possible risk factors in "non-response" to treatment.

\begin{tabular}{|c|c|c|c|c|c|}
\hline GSTP1 Exon5 & Non-responder & Total number of patients & Prevalance (\%) & OR & 95 \% CI \\
\hline wild type & 43 & 59 & 72,9 & - & - \\
\hline heterozygote & 33 & 44 & 75,0 & 0,897 & $0,329-2,447$ \\
\hline mutant & 8 & 10 & 80,0 & 0,673 & $0,085-5,304$ \\
\hline
\end{tabular}

Table 3: Possible risk factors in "non-response" to treatment.

\begin{tabular}{|c|c|c|c|c|c|}
\hline GSTM1 & Non-responder & Total number of patients & Prevalance (\%) & OR & 95 \% CI \\
\hline No & 47 & 64 & 73,4 & - & - \\
\hline Yes & 37 & 49 & 75,5 & 1,132 & $0,435-2,946$ \\
\hline
\end{tabular}

Table 4: Possible risk factors in "non-response" to treatment.

\begin{tabular}{|c|c|c|c|c|c|}
\hline GSTT1 & Non-responder & Total number of patients & Prevalance (\%) & OR & 95 \% CI \\
\hline No & 63 & 85 & 74,1 & - & - \\
\hline Yes & 21 & 28 & 75,0 & 1,157 & $0,374-3,580$ \\
\hline
\end{tabular}

Table 5: Possible risk factors in "non-response" to treatment.

\begin{tabular}{|c|c|c|c|c|c|}
\hline $\begin{array}{c}\text { Cigarette } \\
\text { (pack-year) }\end{array}$ & Non-responder & Total number of patients & Prevalance (\%) & OR & 95 \% CI \\
\hline $\mathbf{0 - 1 9}$ & 11 & 15 & 73,3 & - & - \\
\hline $\mathbf{2 0 - 3 9}$ & 28 & 34 & 82,4 & 1,663 & $0,354-7,815$ \\
\hline $\mathbf{4 0 - 5 9}$ & 12 & 19 & 63,2 & 0,466 & $0,085-2,565$ \\
\hline $\mathbf{6 0 - 7 9}$ & 17 & 22 & 77,3 & 1,369 & $0,278-6,749$ \\
\hline $\mathbf{8 0}$ and above & 16 & 23 & 69,6 & 0,762 & $0,164-3,546$ \\
\hline
\end{tabular}

Table 6: Possible risk factors in "non-response" to treatment.

\begin{tabular}{|c|c|c|c|c|c|}
\hline Alcohol consumption & Non-responder & Total number of patients & Prevalance (\%) & OR & 95 \% CI \\
\hline Non & 56 & 78 & 71,8 & - & - \\
\hline Light & 13 & 16 & 81,3 & 1,289 & $0,297-5,599$ \\
\hline Medium & 4 & 5 & 80,0 & 2,085 & $0,148-29,424$ \\
\hline Heavy & 11 & 14 & 78,6 & 1,974 & $0,457-8,531$ \\
\hline
\end{tabular}

Table 7: Possible risk factors in "non-response" to treatment.

\begin{tabular}{|c|c|c|c|c|c|}
\hline Cancer type & Non-responder & Total number of patients & Prevalance (\%) & OR & 95 \% CI \\
\hline Small cell & 16 & 32 & 50,0 & - & - \\
\hline Non-small cell & 68 & 81 & 84,0 & 5,231 & $2,101-13,021$ \\
\hline
\end{tabular}

Smoking habits of the patients and the rate of their nonresponse to treatment were evaluated at Table 5. Accordingly, it was observed that 15 patients $(73 \%), 34$ patients $(82 \%)$, 19 patients (63\%), 23 patients $(70 \%)$ and 23 patients $(70 \%)$ smoked 0-19 boxes/year, 20-39 boxes/year, 40-59 boxes/year, 60-79 boxes/year and $80 \geq$ boxes/year, respectively. Patients' alcohol ingestion and their non-response rate to treatment were evaluated at Table 6. It was determined that 78 (71\%), 16 (81\%), 5 (80\%) and 14 patients (79\%) were non-drinkers, light drinkers, medium drinkers and heavy drinkers, respectively. Distribution of patients according to the cancer type and their non-response rate to treatment were evaluated at Table 7 . It was determined that 32 (50\%) and 84 (84\%) patients had small-cell lung cancer and nonsmall cell lung cancer, respectively. Patients' alcohol ingestion was evaluated in accordance with their smoking habits and responses to treatment in Table 8. In table 9, smoking habits of the patients were evaluated via their response to treatment for GSTP1 exon6 gene. 


\section{Cancer Therapy \& Oncology International Journal}

Table 8: Possible risk factors in "non-response" to treatment.

\begin{tabular}{|c|c|c|c|c|c|}
\hline \multirow[b]{2}{*}{ Alcohol } & \multirow[b]{2}{*}{ Cigarette (box-year) } & \multicolumn{2}{|c|}{ Response } & \multirow[b]{2}{*}{ Total } & \multirow[b]{2}{*}{ Non-responder Prevelance (\%) } \\
\hline & & Yes & No & & \\
\hline \multirow{5}{*}{ Non } & $0-19$ & 3 & 10 & 13 & 76,9 \\
\hline & $20-39$ & 5 & 17 & 22 & 77,3 \\
\hline & $40-59$ & 6 & 9 & 15 & 60,0 \\
\hline & $60-79$ & 4 & 10 & 14 & 71,4 \\
\hline & 80 and above & 4 & 10 & 14 & 71,4 \\
\hline \multirow{5}{*}{ Light } & $0-19$ & 1 & 1 & 2 & 50,0 \\
\hline & $20-39$ & 1 & 6 & 7 & 85,7 \\
\hline & $40-59$ & 0 & 0 & 0 & \\
\hline & $60-79$ & 0 & 3 & 3 & 100,0 \\
\hline & 80 and above & 1 & 3 & 4 & 75,0 \\
\hline \multirow{5}{*}{ Medium } & $0-19$ & 0 & 0 & 0 & --- \\
\hline & 20-39 & 0 & 2 & 2 & 100,0 \\
\hline & $40-59$ & 0 & 1 & 1 & 100,0 \\
\hline & $60-79$ & 0 & 0 & 0 & --- \\
\hline & 80 and above & 1 & 1 & 2 & 50,0 \\
\hline \multirow{5}{*}{ Heavy } & $0-19$ & 0 & 0 & 0 & --- \\
\hline & $20-39$ & 0 & 3 & 3 & 100,0 \\
\hline & $40-59$ & 1 & 2 & 3 & 66,7 \\
\hline & $60-79$ & 1 & 4 & 5 & 80,0 \\
\hline & 80 and above & 1 & 2 & 3 & 66,7 \\
\hline
\end{tabular}

Table 9: Possible risk factors in "non-response" to treatment.

\begin{tabular}{|c|c|c|c|c|c|}
\hline \multirow[b]{2}{*}{ Cigarette (box-year) } & \multirow[b]{2}{*}{ Ex6 } & \multicolumn{2}{|c|}{ Response } & \multirow{2}{*}{ Total } & \multirow[b]{2}{*}{ Non-responder Prevelance (\%) } \\
\hline & & Yes & No & & \\
\hline \multirow{3}{*}{$0-19$} & w & 3 & 8 & 11 & 72,7 \\
\hline & $\mathrm{h}$ & 1 & 1 & 2 & 50,0 \\
\hline & $\mathrm{m}$ & 0 & 2 & 2 & 100,0 \\
\hline \multirow{3}{*}{ 20-39 } & w & 6 & 18 & 24 & 75,0 \\
\hline & $\mathrm{h}$ & 0 & 6 & 6 & 100,0 \\
\hline & $\mathrm{m}$ & 0 & 4 & 4 & 100,0 \\
\hline \multirow{3}{*}{ 40-59 } & w & 6 & 7 & 13 & 53,8 \\
\hline & $\mathrm{h}$ & 0 & 0 & 0 & yok \\
\hline & $\mathrm{m}$ & 1 & 5 & 6 & 83,3 \\
\hline \multirow{3}{*}{$60-79$} & $\mathrm{w}$ & 5 & 15 & 20 & 75,0 \\
\hline & $\mathrm{h}$ & 0 & 1 & 1 & 100,0 \\
\hline & $\mathrm{m}$ & 0 & 1 & 1 & 100,0 \\
\hline \multirow{3}{*}{80 and above } & $\mathrm{w}$ & 6 & 10 & 16 & 62,5 \\
\hline & $\mathrm{h}$ & 1 & 5 & 6 & 83,3 \\
\hline & $\mathrm{m}$ & 0 & 1 & 1 & 100,0 \\
\hline
\end{tabular}




\section{Cancer Therapy \& Oncology International Journal}

\section{Discussion}

This study is conducted to search the effects of GSTM1, GSTT1 and GSTP1 isoenzymes of glutathione S-transferase enzymes, alcohol ingestion and smoking on response to treatment in lung carcinoma patients receiving platinum-based chemotherapy. GSTP1 is the most strongly expressed isoenzyme in the human lung. GSTM1 and GSTT1 isoenzymes are expressed in the lung, though lesser $[22,23]$. GSTP1 is known as to be the most expressed GST in non-small cell lung tumors [24]. It was determined that GSTP1 levels of drug resistant tumors were high [25]. Among these, non-small cell lung tumors are remarkable, in particular [1, 26-28]. It is argued that GSTP1 directly participates in the detoxification of platinum components and that it plays a significant role in both intrinsic and acquired resistance to platinum components $[7,29]$. However, there are studies demonstrating that platinum resistance is not associated with GSTP1 [30,31]. Similar contradictory results were presented for ovarian carcinoma $[32,33]$. One of the important reasons for not being able to demonstrate the correlation between GSTP1 expression and platinum components at any time, may be the polymorphism of GSTP1 gene. It is well-known that GSTP1 gene is polymorphic. In one of the two mutations of GSTP1 gene (Ile $105 \mathrm{Val}$ ), a single nucleotide substitution (A-G) at position 313 results in replacing isoleucine with valine and thus enzyme activity diminishes. However, heterozygouts display mediumlevel enzyme activity.

Moreover, it is reported that GSTM1 and GSTT1 may be effective in the formation of several carcinomas, including lung carcinoma, and in response to treatments [34-36]. Since GSTM1 and GSTT1 genes are also polymorphic, lack of these genes results in loss of enzyme activities [37]. In this study, the responses to cisplatine based chemotherapy of homozygous and heterozygous patients with GSTP1 exon5 variant allele were observed to be like the responses of the patients carrying wild type genotype. GSTP1 develops resistance to etoposide, chlorambucil, melphalan and adriamycin as well as to cisplatine and carboplatine $[9,38]$. Therefore, the beneficial effect of GSTP1 exon5 variant allele cannot be attributed to a specific drug concerning treatment response, for instance on the response to cisplatine, but its effect can also be attributed to the combinations including these drugs concerning the response that may be received. However its benefit on the chemotherapy applied with drugs other than those mentioned (eg. 5-Florouracil) or with other combinations of drugs will remain undetermined until it is demonstrated that the mentioned drugs are detoxified by GSTP1. The reasons why results obtained in this study are different from those obtained on colon and breast cancers and leukemia may be that number of patients is less, different resistance mechanisms are dominant, different tumor types and chemotherapy regimens applied according to the cancer types. Furthermore, it was determined that GSTP1 genotypes who responded and did not respond to chemotherapy did not have a significant relation with age, gender and the phase of the disease.

The reason why GSTM1 and GSTT1 polimorphisms do not have effect on chemotherapy in non-small cell lung cancer patients may be that they are expressed in lung in small quanities. Similar findings were identified in colon cancer patients receiving paltinum based treatment [39]. It is reported that the expressions of these enzymes are less in colon tumors as the case be in lung tumors and that on the other hand, GSTP1 is expressed more [40]. On the other hand, data is not sufficient about the predictive role of GSTs on the efficiency of cisplatine based drugs. It was demonstrated by using rats that GST Mu displayed resistance to cisplatin [41]. However, it was not displayed that these were the subtrates of human GSTM1. Additionally, the role of GSTT1 in the detoxification of cisplatinum is unknown. However, both of these two GSTs may function during the inactivation of lipid peroxides $[42,43]$. Thus, it may be considered that these GSTs may contribute to develop resistance by reducing the cytotoxic effects of alkylating agents through this method. However this study gives the impression that this case is not valid.

It is reported that in glioma cancer patients, GSTM1 gene, together with GSTP1 increases the responses to chemotherapy including nitrosourea alkylating agents [44]. However, in our study, doublet and triplet combinations of GSTM1, GSTP1 and GSTT1 genotypes did not demonstrate any effect on the response to chemotherapy as a whole. When the structure of relation between the patients'response or non-response to treatment and their gene isoenzymes was examined, it was observed that those who had GSTP1 exon 6 mutant genotypes responded to treatment 9 times more than those having GSTP1 exon wild type genes. Although it was observed that patients smoking 80 or more boxes a year responded to treatment, it is clear from the table that these patients' rate of having mutant or heterozygote genes is low. Thus, it is obvious that the evaluations to be conducted only according to the frequency of smoking will be mistaken. Under these circumstances, it is displayed that wild type genes have positive effect on the response to treatment. This results yields that it is important to evaluate the effect of combination of GST genotype, alcohol ingestion amount, smoking frequency on the response to treatment.

In conclusion, statistically significant relation could not be established between the the effects of GSTM1, GSTT1 and GSTP1 isoenzymes of glutathione S-transferase enzymes and ethyl alcohol ingestion and smoking on response to treatment in lung carcinoma patients receiving platinum-based chemotherapy. However, it is observed in terms of response to treatment that GSTP1 Exon 6 gene's being wild type, low or little alcohol ingestion, being a non smoker or low smoking decrease the risk factor. 


\section{Cancer Therapy \& Oncology International Journal}

\section{Acknowledgment}

I would like to thank Prof. Dr. Mümtaz İşcan, Prof.Dr. Meral Gülhan, Assoc.Prof.Dr. Ahmet Oğuz Ada, Assoc.Prof.Dr. Soner Çankaya, Dr. Sibel Alpar, Dr. Metin Özsoy and Specialist Pharmacist Figen Hançer for their helpful advice during this study.

\section{References}

1. Bai F, Nakanishi Y, Kawasaki M, Takayama K, Yatsunami J, et al. (1996) Immunohistochemical expression of glutathione S-transferase -Pi Ccan predict chemotherapy response in patients with nonsmall cell lung carcinoma. Cancer 78(3): 416-421.

2. Giovino GA (2002) Epidemiology of tobacco use in the United States. Oncogen 21(48): 7326-7340.

3. Rosell R, Cecere F, Santarpia M, Reguart N, Taron M (2006) Predicting the outcome of chemotherapy for lung cancer. Curr Opin Pharmacol 6(4): 323-331.

4. Boyer Td, Kenney Wc (1985) Preparation, characterization and Properties of glutathione S-transferases. In: Biochemical Pharmacolog and Toxicology, (Eds) Vessey ZD, John Wiley \& Sons, New York, USA.

5. Hayes JD, Strange RC (2000) Glutathione S-transferase polymorphisms and their biological consequences. Pharmacology 61(3): 154-166.

6. Yang M, Coles BF, Delongchamp R, Lang NP, Kadlubar FF (2002) Effects of the ADH3, CYP2E1, and GSTP1 genetic polymorphisms on their expressions in Caucasian lung tissue. Lung cancer 38(1): 15-21.

7. Goto S, Lida T, Cho S, Oka M, Kohno S, Kondo T (1999) Overexpression of glutathione S-transferase pi enhances the adduct formation of cisplatin with glutathione in human cancer cells. Free Radic Res 31(6): 549-558.

8. Board P, Coggan M, Johnston P, Ross V, Suzuki T, et al. (1990) Genetic heterogeneity of the human glutathione transferases: a complex of gene families. Pharmacol Ther 48(3): 357-369.

9. Pandya U, Srivastava SK, Singhal SS, Pal A, Awasthi S, et al. (2000) Activity of allelic variants of Pi class human glutathione S-transferase toward chlorambucil. Biochem Biophys Res Commun 278((1): 258262

10. Rebbeck TR (1997) Molecular epidemiology of the human glutathione S-transferase genotypes GSTM1 and GSTT1 in cancer susceptibility. Cancer Epidemiol Biomarkers Prev 6(9): 733-743.

11. Brown LAS, Harris FL, Bechara R, Guidot DM (2001) Effect of chronic ethanol ingestion on alveolar type II cell: glutathione and inflammatory mediator-induced apoptosis. Alcoholism: Clinical and Experimental Research 25(7): 1078-1085.

12. Liang Y, Yeligar Sm, Brown Las (2012) Chronic Alcohol -Abuse-Induced Oxidative Stress in the Development of Acute Respiratory Distress Syndrome. Scientific World Journal. 2012: 740308.

13. Lee H, Jang Is, Park J, Kim Sh, Baek Sy, et al. (2013) Systemic immune modulation induced by alcoholic beverage intake in obese-diabetes (db/db) mice. Food Chem Toxicol 53: 286-293.

14. Andrade Mc, Albernaz Mj, Araújo Ms, Santos Bp, Teixeira-Carvalho A, et al. Short-term administration of ethanol in mice deviates antigen presentation activity towards B cells. Scand J Immunol 70(3): 226-237.

15. An Y, Kiang A, Lopez Jp, Kuo Sz, Yu Ma, et al. (2012) Cigarette smoke promotes drug resistance and expansion of cancer stem cell-like side population. PLoS One 7(11): e47919.

16. Treviño Jg, Pillai S, Kunigal S, Singh S, Fulp Wj, et al. (2012) Nicotine induces inhibitor of differentiation- 1 in a Src-dependent pathway promoting metastasis and chemoresistance in pancreatic adenocarcinoma. Neoplasia 14(12): 1102-1114.

17. Samanta D, Kaufman J, Carbone DP, Datta PK (2012) Long-Term Smokigng Mediated Down Regulation of Smad3 İnduces Resistance To Carboplatin İn Non-Smal Cell Lung Cancer. Neoplasia 16(7): 644655.

18. Dasari S, Tchounwou PB (2014) Cisplatin in cancer therapy: molecular mechanisms of action. Eur J Pharmacol 740: 364-378.

19. Miller Ma, Korn D, Wang Ts (1988) The evolutionary conservation of DNA polymerase alpha. Nucleic Acids Res 16(16): 7961-7973.

20. Abdel- Rahman Sz, El-Zein Ra, Anwar Wa, Au Ww (1996) A multiplex PCR procedure for polymorphic analysis of GSTM1 and GSTT1 genes in population studies. Cancer Lett 107(2): 229-233.

21. Park JY , Schantz SP , Stern JC , Kaur T , Lazarus P (1999) Association between glutathione $\mathrm{S}$-transferase pi genetic polymorphisms and oral cancer risk. Pharmacogenetics 9(4): 497-504.

22. Anttila S, Hirvonen A, Vainio $H$, Husgafvel-Pursiainen $K$, Hayes JD, et al. (1993) Immunohistochemical localization of glutathione S-transferases in human lung. Cancer Res 53(23): 5643-5648.

23. Cantley Am, Smith Ca, Wallace Wa, Yap Pl, Lamb D, et al. (I994) Heterogeneous expression of and polymorphic genotype of glutathione S-transferase in human lung. Thorax 49(10): 1010-1014.

24. Howie Af, Forrester Lm, Glancey Mj, Schlager Jj, Powis G, et al. (1990) Glutathione S-transferase and glutathione peroxidase expression in normal and tumor human tissues. Carcinogenesis 11(3): 451-458.

25. Tsuchida S, Sato K (1992) Glutathione transferases and cancer. Crit Rev Biochem Mol Biol 27(4-5): 337-384.

26. Hida T, Kuwabara M, Arıyoshı Y, Takahashı T, Sugurra T, et al. (1994) Serum glutathione S-transferase -Pi level as a tumor marker for nonsmall cell lung cancer. Potential predictive value in chemotherapeutic response. Cancer 73(5): 1377-1382.

27. Araı T, Yasuda Y, Takaya T, Hayakawa K, Toshıma S, et al. (2000) Immunohistochemical expression of glutathione transferase-pi in untreated primary non-small-cell lung cancer. Cancer detect prevent 24(3): 252-257.

28. Ogurı T, Fujıwara Y, Katoh O, Daga H, Ishıkawa N, et al. (2000) Glutathione S-transferase- $\mathrm{Pi}$ genexpression and platinum drug exposure in human lung cancer. Cancer Lett 156(1): 93-99.

29. Ban N, Takahashı Y, Takayama T, Kura T, Katahıra T, et al. (1996) Transfection of glutathione S-transferase (GST) -Pi antisense complementary DNA increases the sensitivity of a colon cancer cell line to adriamycin, cisplatin, melphalan, and etoposide. Cancer Res 56(15): 3577-3582.

30. Mıyara H, Hıda T, Nıshıda K, Takahashı T, Sugıura T, et al. (1996) Modification of chemo-radiosensitivity of a lung cancer cell line by introduction of the glutathione S-transferase pi gene. Jpn J Clin Oncol 26(1): 1-5.

31. Unsal M, Akpolat I, Kandemir B (2003) Glutahione-S tansferse-pi expression in non small cell lung cancer in the assessment of response to chemotherapy. Saudi Med J 24(5): 493-498.

32. Hamaga SI, Kamada M, Furumoto H, Hirao T, Aono T (1994) Expression of glutathione S-transferase -pi in human ovarian cancer as an indicator of resistance to chemotherapy. Gynecol Oncol 52: 313-319.

33. Van Der Zee Agj, Hollema H, Suurmaijer Ajh, Krans M, Sluiter Wj, et al. (1995) Value of P-glycoprotein, glutathione S-transferase pi, c-erbB-2, and p53 and prognostic factors in ovarian carcinomas. J Clin Oncol 13: 70-78. 


\section{Cancer Therapy \& Oncology International Journal}

34. Hengster Jg, Arand M, Herrero Me, Oesch F (1998) Polymorphisms in $\mathrm{N}$-acetyltransferases, glutathione S-transferases, microsomal epoxide hydrolase and sulfotransferases: influence on cancer susceptibility. Recent Results Cancer Res 154: 47-85.

35. Stucker I, Hirvonen A, De Wazıers I, Cabelguenne A, Mitrlınen K, et al. (2002) Genetic polymorphisms of glutathione S-transferases as modulators of lung cancer susceptibility. Carcinogenesis, 23(9): 14751481

36. Sorensen M, Autrup H, Tjonneland A, Overvad K, Raaschou-Nielsen O (2004) Glutathion S-transferase T1 null e genotype is associated with an increased risk -of lung cancer. Int J Cancer 110: 219-224.

37. London Sj, Yuan Jm, Chung Fl, Gao Yt, Coetzee Ga, et al. (2000) Isothiocyanates, glutathione S-transferase M1 and T1 polymorphisms, and lung cancer risk: a prospective study in Shanghai, China. Lancet 356(9231): 724-729.

38. Nakagawa K, Yokota J, Wada M, Sasakı Y, Fujıwara Y, et al. (1988) Levels of glutathione S-transferase Pi mRNA in human lung cancer cell lines correlate with the resistance to cis-platin and carbop|atin. Jpn J Cancer Res (Gann) 79(3): 301-304.

39. Stoehlmacher J, Park Dj, Zhang W, Groshen S, Tsao-Wei Dd, et al. (2002) Association between glutathione S-transferase $\mathrm{Pl}, \mathrm{Tl}$, and $\mathrm{Ml}$ genetic polymorphism and survival of patients with metastatic colorectal cancer. J Natl Cancer Inst 94(12): 936-942.
40. Moscow JA, Fairchild CR, Madden MJ, Ransom DT, Wieand HS, et al. (1989) Expression of anionic glutathione S-transferase and P-glycoprotein genes in human tissues and tumors. Cancer Res 49(6): $1422-1428$

41. Puchalski Rb, Fahl We (1990) Expression of recombinant glutathione S-transferase pi, Ya, or Yb1 confers resistance to alkylating agents. Proc Natl Acad Sci USA 87(7): 2443-2447.

42. Ketterer B, Meyer Dj (1989) Glutathione transferases: a possible role in the detoxication and repair of DNA and lipid hydroperoxides. Mutat Res 214(1): 33-40.

43. Ketterer B., Mulder GJ (1990) Glutathione conjugation. Conjugatian Reactions in Drug Metabolisn, Mulder G.J. Taylor and Françis, London, New York-Phidelphia, USA, pp. 308-364.

44. Okcu Mf, Selvan M, Wang Le, Stout L, Erana R, et al. (2004) Glutathione S-transferase polymorphisms and survival in primary malignant glioma. Clin Cancerr Res 10(8): 2618-2625

\section{Your next submission with Juniper Publishers will reach you the below assets}

- Quality Editorial service

- Swift Peer Review

- Reprints availability

- E-prints Service

- Manuscript Podcast for convenient understanding

- Global attainment for your research

- Manuscript accessibility in different formats

(Pdf, E-pub, Full Text, Audio)

- Unceasing customer service

Track the below URL for one-step submission https://juniperpublishers.com/online-submission.php 